\title{
AIDS-Related Kaposi Sarcoma Poor Risk
}

National Cancer Institute

\section{Source}

National Cancer Institute. AIDS-Related Kaposi Sarcoma Poor Risk. NCI Thesaurus. Code C134986.

The following combination of tumor and systemic illness status define poor risk AIDSrelated Kaposi sarcoma: T1 S1. T1: Widespread tumor. S1: Systemic illness is present. (American Cancer Society) 